\title{
High serum nitric oxide levels in patients with severe leptospirosis
}

\author{
Elves A.P. Maciel ${ }^{\text {a }}$, Daniel A. Athanazio ${ }^{\text {a,b }}$, Eliana A.G. Reis ${ }^{\text {a }}$, Fernando Q. Cunha ${ }^{\text {c }}$, \\ Adriano Queiroz $^{\mathrm{a}, \mathrm{b}}$, Deusdelia Almeida ${ }^{\mathrm{a}, \mathrm{b}}$, Alan J.A. McBride ${ }^{\mathrm{a}}$, \\ Albert I. Ko ${ }^{\text {a,d }}$, Mitermayer G. Reis ${ }^{\text {a,b,* }}$ \\ a Gonçalo Moniz Research Centre, Oswaldo Cruz Foundation, Ministry of Health, Salvador, Brazil \\ b Federal University of Bahia, Salvador, Brazil \\ c Ribeirao Preto Faculty of Medicine, University of Sao Paulo, Ribeirao Preto, Brazil \\ ${ }^{\mathrm{d}}$ Division of International Medicine and Infectious Disease, Weill Medical College of Cornell University, New York, USA
}

Received 14 July 2006; received in revised form 7 November 2006; accepted 19 November 2006

Available online 2 January 2007

\begin{abstract}
Leptospirosis is a globally distributed zoonosis of major public health importance and is associated with severe disease manifestations such as acute renal failure and pulmonary haemorrhage syndrome. However, the extent to which the pathogenesis of leptospirosis mimics sepsis caused by Gram-negative bacteria remains unknown. The aim of this study was to evaluate serum levels of nitric oxide (NO) in patients diagnosed with severe leptospirosis. Sera from 35 confirmed cases of severe leptospirosis and 13 healthy subjects were analysed. Patients with severe leptospirosis had significantly higher NO levels compared to healthy individuals $(30.82 \pm 10.90 \mu \mathrm{M}$ versus $3.86 \pm 1.34 \mu \mathrm{M}, P<0.001)$, indicating that this immune mediator plays a role in the underlying systemic inflammatory response.
\end{abstract}

(C) 2006 Elsevier B.V. All rights reserved.

Keywords: Leptospirosis; Nitric oxide; Acute renal failure; Pulmonary haemorrhage

Leptospirosis is a widespread zoonosis caused by pathogenic spirochetes from the Leptospira genus. Transmission to humans is accidental and typically occurs through contact with mud or water contaminated with urine of infected animals, principally rodents. Traditionally a sporadic disease confined to a rural setting, leptospirosis now causes yearly epidemics in urban living conditions associated with extreme poverty (Johnson et al., 2004; Karande et al., 2003; Ko et al., 1999; LaRocque et al., 2005; Sarkar et al., 2002). Outbreaks

\footnotetext{
* Corresponding author at: Centro de Pesquisas Gonçalo Moniz CPqGM, Rua Waldemar Falcão, 121, Candeal, CEP: 40296-710 Salvador, Bahia, Brazil. Tel.: +55 713176 2200; fax: +55 7131762326 .

E-mail address: miter@cpqgm.fiocruz.br (M.G. Reis).
}

are also associated with water sports and recreational activities that result in exposure to pathogenic Leptospira (Haake et al., 2002). The clinical spectrum ranges from a mild anicteric disease to the more severe forms such as Weil's syndrome (jaundice, haemorrhagic diathesis and acute renal failure), associated with a $10 \%$ mortality and severe pulmonary haemorrhage syndrome (SPHS), for which the case fatality rate can be $>50 \%$ (McBride et al., 2005).

The underlying pathogenic mechanisms associated with the severe manifestations of leptospirosis are poorly understood but it is assumed that a generalized endothelial dysfunction, as observed in experimental and human leptospirosis, is the main pathogenic mechanism of tissue damage (De Brito et al., 1979; Nicodemo et al., 1997). A similar process occurs in sepsis and is mediated 
by pro-inflammatory cytokines, including interleukins IL-1, IL-6 and tumour necrosis factor alpha (TNF- $\alpha$ ) (Cohen, 2002). These pro-inflammatory cytokines lead to increased expression of inducible nitric oxide synthase (iNOS) and increased production of nitric oxide (NO) in patients with sepsis. Leptospira components, such as lipopolysaccharide and glycolipoprotein, have been reported to activate leukocytes and stimulate the production of pro-inflammatory cytokines such as TNF$\alpha$ and/or IL-8 (Cinco et al., 1996; Diament et al., 2002; Werts et al., 2001; Yang et al., 2002). Furthermore, it has been reported that high levels of TNF- $\alpha$ were associated with lethal outcomes in hospitalised patients (Tajiki and Salomao, 1996), modulated, to some degree, by IL-10 (Tajiki et al., 1997). Nevertheless, it remains unclear as to the extent, if any, that sepsis and leptospirosis share similar mechanisms. As NO is considered to be a major mediator of endothelial dysfunction in sepsis, we determined NO levels in serum from patients with severe leptospirosis and compared them to those obtained from healthy individuals.

Acute phase serum samples were collected from 35 patients with confirmed severe leptospirosis from Couto Maia Hospital, the infectious disease referral hospital in Salvador, Bahia, Brazil during the period April 2000 to September 2002. Patients who fulfilled the criteria for severe leptospirosis (clinical symptoms compatible with leptospirosis, jaundice, renal insufficiency (oliguria, creatinine $>1.5 \mathrm{mg} / \mathrm{dl}$, urea $>150 \mathrm{mg} / \mathrm{dl}$ ), acute fever and haemorrhagic manifestations) were eligible for inclusion in the study. Non-hospitalized patients or those who did not fulfill the selection criteria were excluded from the study. Diagnosis was confirmed by the microagglutination test (MAT) with the following criteria: a four-fold or greater rise in titre between paired serum samples; seroconversion (initial MAT titre of $<100$ increasing to $\geq 200$ ); or a single serum titre $\geq 800$ were considered positive. Demographic, clinical and laboratory data were available from hospital charts. Control serum samples were collected from 13 healthy individuals. Informed consent was obtained from each participant prior to the collection of blood according to protocols approved by the Ethical Committee of the Oswaldo Cruz Foundation.

Serum NO levels were determined by the measurement of NOx (nitrite and nitrate) after enzymatic reduction of nitrate with nitrate reductase, as previously described (Tavares-Murta et al., 2002). Briefly, $50 \mu \mathrm{l}$ of undiluted serum was incubated with the same volume of reductase buffer $(0.1 \mathrm{M}$ potassium phosphate, $\mathrm{pH}$ 7.5 , containing $1 \mathrm{mM}$ nicotinamide adenine dinucleotide phosphate, $10 \mathrm{mM}$ flavin adenine dinucleotide and four units of nitrate reductase $/ \mathrm{ml}$ ) for $20 \mathrm{~h}$ at $37^{\circ} \mathrm{C}$. The nitrite
$\left(\mathrm{NO}_{2}{ }^{-}\right)$concentration was determined using the Griess method (Green et al., 1981).

Comparison of the NO levels between cases and control subjects was assessed using the non-parametric Mann-Whitney test. The correlation between the NO levels and serum creatinine was evaluated using the Spearman correlation co-efficient. SPSS 10.0 and GraphPad Prism 4.03 software packages were used for all statistical analyses. A $P<0.05$ was considered significant. Standard deviations were included where appropriate in the text as \pm values.

Among the 35 leptospirosis patients, 33 were male and the mean age was $35.5 \pm 13.7$ (range of 14-71 years). The most frequent clinical manifestations on hospital admission were jaundice (33/35) and fever (30/35). Respiratory insufficiency (respiratory rate greater than 28 per min) occurred in four patients. Shock, defined by a systolic blood pressure less than $90 \mathrm{mmHg}$, was observed in five patients. Serum creatinine levels on admission were $>1.5 \mathrm{mg} / \mathrm{dl}$ in 10 patients. The mean maximum creatinine level measured during hospitalization was $4.92 \pm 2.41 \mathrm{mg} / \mathrm{dl}$ and $97.1 \%$ (32/35) of patients had levels $>1.5 \mathrm{mg} / \mathrm{dl}$. Eleven patients were subject to intraperitoneal dialysis for, on average, 3 days (range 1-6 days). All patients survived and the average time of hospitalization was 8 days (range 3-27 days). The control individual group included 10 males, 3 females with an average age of $24.7 \pm 3.2$ (range $19-30$ years of age). The mean NO level in patients with acute leptospirosis was $30.82 \pm 10.90 \mu \mathrm{M}$ compared to $3.86 \pm 1.34 \mu \mathrm{M}$ among control subjects $(P<0.001)$. Using a cut-off based on the mean NO level of the control group plus two standard deviations $(6.54 \mu \mathrm{M})$, resulted in all patients having detectable NO levels above the cut-off (Fig. 1).

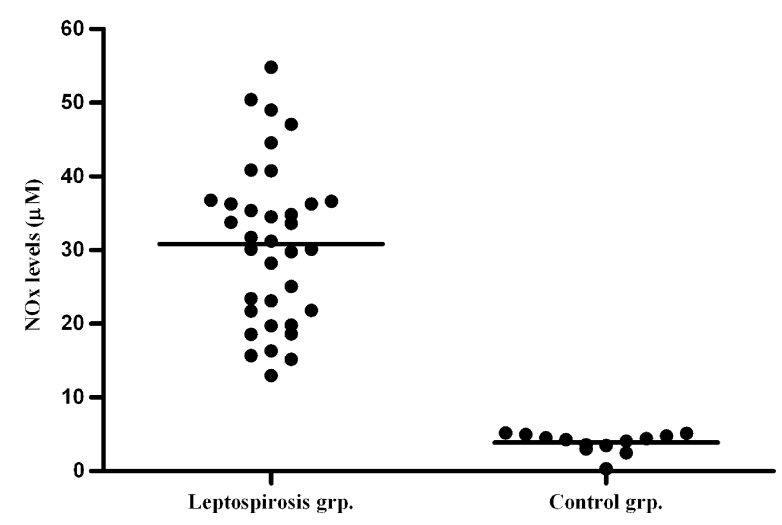

Fig. 1. Serum nitric oxide levels in patients with leptospirosis and in healthy adult individuals. A non-parametric Mann-Whitney test comparing NO levels was highly significant $(P<0.001)$, horizontal bars represent the mean value for each group. 
The NO levels reported in this study are lower than reported by Tavares-Murta et al. (2002). Variable levels of NO, as detected by the Griess reaction, have been reported in samples from healthy individuals. Nitrite was found to range from 0 to $20 \mu \mathrm{M}$, and nitrate to range from 0 to $108 \mu \mathrm{M}$ in the blood of healthy individuals. Similar ranges have been noted even when an automated process is used to measure the Griess reaction. Explanations for these variations in nitrite and nitrate are detailed extensively in a recent review (Tsikas, 2006). Factors include preparation of the blood prior to the Griess reaction, stability of reaction intermediates, formation of more than one dye, $\mathrm{pH}$ and temperature. Differences in sample handling and storage procedures may account for differences NO levels of healthy individuals and those reported in the literature. However, in our study, samples from patient and control groups were processed and analysed in a standardized manner.

A recognised marker for the severity of leptospirosis in patients is the estimation of renal dysfunction based on serum creatinine values (Ko et al., 1999; Daher et al., 1999; Dupont et al., 1997; Esen et al., 2004; Panaphut et al., 2002; Tantitanawat and Tanjatham, 2003). Therefore, to analyse the relationship between serum NO levels and severe leptospirosis, NO levels were compared with the maximum serum creatinine value during hospitalization. No significant correlation was observed (Spearman $r \mathrm{~s}=0.307, P=0.073$ ). However, age was found to correlate positively with maximum serum creatinine values $(r \mathrm{~s}=0.49, P=0.003)$. As NO levels are known to correlate inversely with age (Anstey et al., 1999; Di Massimo et al., 2006; Kleinbongard et al., 2006; Rath and Krantz, 1942; Toprakci et al., 2000), a partial correlation analysis was performed. After controlling for age, a significant correlation between NO levels and maximum serum creatinine value was observed (partial correlation co-efficient $=0.34, P=0.047$, Fig. 2). Alternate markers of disease severity, including time of hospitalization $(r s=0.03, P=0.86)$ and MAT titre ( $r s=-0.19, P=0.26$ ), were not found to correlate with NO levels.

The pathophysiological evidence for a systemic inflammatory response in leptospirosis to date is limited. As mentioned previously, TNF- $\alpha$ levels have been linked to the severity of the disease (Tajiki and Salomao, 1996; Tajiki et al., 1997), as has been reported in cases of sepsis (Hotchkiss and Karl, 2003). Importantly, elevated serum NO levels have been correlated with severe forms of meningococcemia and other systemic inflammatory syndromes of infectious aetiology (Baines et al., 1999; Mitaka et al., 2003). In addition, among 10 patients with severe leptospirosis studied in Thailand, 6

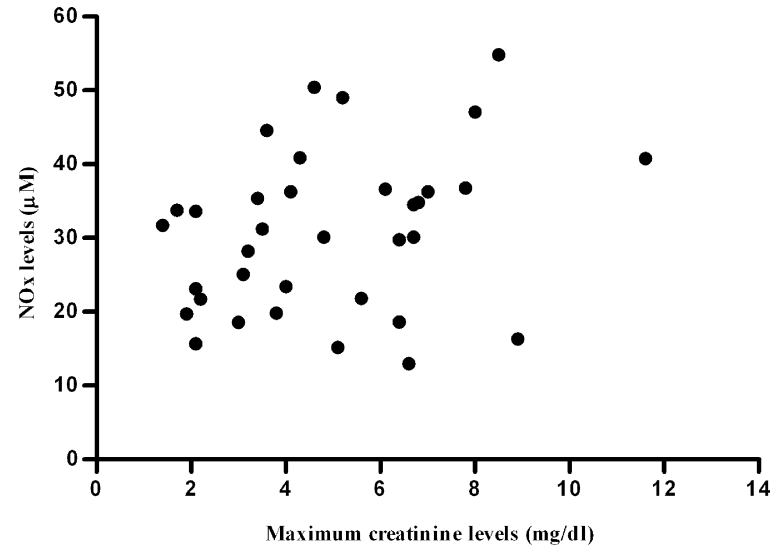

Fig. 2. Correlation between maximum serum creatinine values during hospitalization and nitric oxide (NO) levels in 35 patients with severe leptospirosis.

displayed a haemodynamic pattern similar to sepsis with a high cardiac index and low systemic vascular resistance (Siriwanij et al., 2005). In this study, serum NO levels were significantly elevated in patients with severe leptospirosis, indicating that NO is a major component of the underlying systemic inflammatory syndrome. Previous evidence of a role for NO in leptospirosis include reports of an increase in iNOS gene transcription in murine proximal tubular cells after exposure to outer membrane extracts of $L$. santarosai, that is dependent on Toll-like receptor 2 (Yang et al., 2002, 2006). A recent case report from Taiwan provided immunohistochemical evidence by demonstrating that enhanced iNOS expression in lung tissue was with concurrent diffuse endothelial damage (Yang and Hsu, 2005).

The positive significant correlation between serum creatinine and serum NO levels reported here suggests a possible role for $\mathrm{NO}$ as a mediator in the organic dysfunctions observed in severe leptospirosis. NO is implicated in endothelial dysfunction and renal medullary transport inhibition (Beltowski et al., 2003; Fink and Delude, 2005), both central issues in leptospirosis (Lin et al., 1999), thus it is plausible to speculate that increased serum NO levels are at least an additional, if not a primary pathway leading to the peculiar pattern of renal insufficiency observed in leptospirosis. The mechanism of acute renal failure in leptospirosis is different to that observed in sepsis. Leptospirosis initially causes a nonoliguric hypokalemic form of ARF which progresses to oliguric renal failure with severe volume depletion. Furthermore, progression of infection to severe disease manifestations and development of oliguric renal failure is prolonged in leptospirosis as compared with Gramnegative sepsis, and may be a possible explanation for 
the observed correlation between NO and serum creatinine. In addition, none of the patients died so conclusions cannot be drawn on the role of $\mathrm{NO}$ as a prognostic factor for case fatality. Conclusions cannot be drawn for the role of NO in mild leptospirosis since all study subjects were hospitalized patients with severe disease manifestations. In summary, we report that serum levels of nitric oxide are markedly increased in patients with severe leptospirosis, while its relationship with pathogenesis, including mechanisms of renal failure, deserves further study. Studies of larger patient groups will be important to evaluate the potential role of NO as a prognostic marker for mortality and other clinical outcomes and as a potential target for pharmacological control in cases of severe leptospirosis.

\section{Acknowledgments}

This work was supported by grants from FINEP/PRONEX (4196086200), Oswaldo Cruz Foundation (0250.250.102), Brazilian National Research Council (300.861/96-6) and US National Institutes of Health (grants AI-052473, TW00919). E.A.P.M. received a Ph.D. scholarship from the Bahia State Foundation for the Support of Research (FAPESB).

\section{References}

Anstey, N.M., Weinberg, J.B., Wang, Z., Mwaikambo, E.D., Duffy, P.E., Granger, D.L., 1999. Effects of age and parasitemia on nitric oxide production/leukocyte nitric oxide synthase type 2 expression in asymptomatic, malaria-exposed children. Am. J. Trop. Med. Hyg. 61, 253-258.

Baines, P.B., Stanford, S., Bishop-Bailey, D., Sills, J.A., Thomson, A.P., Mitchell, J.A., Fear, S.C., Hart, C.A., Petros, A.J., 1999. Nitric oxide production in meningococcal disease is directly related to disease severity. Crit. Care Med. 27, 1187-1190.

Beltowski, J., Marciniak, A., Wojcicka, G., Gorny, D., 2003. Nitric oxide decreases renal medullary $\mathrm{Na}+\mathrm{K}+$-ATPase activity through cyclic GMP-protein kinase G dependent mechanism. J. Physiol. Pharmacol. 54, 191-210.

Cinco, M., Vecile, E., Murgia, R., Dobrina, P., Dobrina, A., 1996. Leptospira interrogans and Leptospira peptidoglycans induce the release of tumor necrosis factor alpha from human monocytes. FEMS Microbiol. Lett. 138, 211-214.

Cohen, J., 2002. The immunopathogenesis of sepsis. Nature 420, 885-891.

Daher, E., Trevisan Zanetta, D.M., Cavalcante, M.B., Abdulkader, R.C.R.M., 1999. Risk factors for death and changing patterns in leptospirosis acute renal failure. Am. J. Trop. Med. Hyg. 61, 630-634.

De Brito, T., Bohm, G.M., Yasuda, P.H., 1979. Vascular damage in acute experimental leptospirosis of the guinea-pig. J. Pathol. 128, 177-182.

Di Massimo, C., Scarpelli, P., Di Lorenzo, N., Caimi, G., di Orio, F., Ciancarelli, M.G., 2006. Impaired plasma nitric oxide availability and extracellular superoxide dismutase activity in healthy humans with advancing age. Life Sci. 78, 1163-1167.

Diament, D., Brunialti, M.K., Romero, E.C., Kallas, E.G., Salomao, R., 2002. Peripheral blood mononuclear cell activation induced by Leptospira interrogans glycolipoprotein. Infect. Immun. 70, 1677-1683.

Dupont, H., Dupont-Perdrizet, D., Perie, J.L., Zehner-Hansen, S., Jarrige, B., Daijardin, J.B., 1997. Leptospirosis: prognostic factors associated with mortality. Clin. Infect. Dis. 25, 720-724.

Esen, S., Sunbul, M., Leblebicioglu, H., Eroglu, C., Turan, D., 2004. Impact of clinical and laboratory findings on prognosis in leptospirosis. Swiss Med. Wkly. 134, 347-352.

Fink, M.P., Delude, R.L., 2005. Epithelial barrier dysfunction: a unifying theme to explain the pathogenesis of multiple organ dysfunction at the cellular level. Crit. Care Clin. 21, 177-196.

Green, L.C., Ruiz de Luzuriaga, K., Wagner, D.A., Rand, W., Istfan, N., Young, V.R., Tannenbaum, S.R., 1981. Nitrate biosynthesis in man. Proc. Natl. Acad. Sci. U.S.A. 78, 7764-7768.

Haake, D.A., Dundoo, M., Cader, R., Kubak, B.M., Hartskeerl, R.A., Sejvar, J.J., Ashford, D.A., 2002. Leptospirosis, water sports, and chemoprophylaxis. Clin. Infect. Dis. 34, e40-e43.

Hotchkiss, R.S., Karl, I.E., 2003. The pathophysiology and treatment of sepsis. N. Engl. J. Med. 348, 138-150.

Johnson, M.A., Smith, H., Joeph, P., Gilman, R.H., Bautista, C.T., Campos, K.J., Cespedes, M., Klatsky, P., Vidal, C., Terry, H., Calderon, M.M., Coral, C., Cabrera, L., Parmar, P.S., Vinetz, J.M., 2004. Environmental exposure and leptospirosis, Peru. Emerg. Infect. Dis. 10, 1016-1022.

Karande, S., Bhatt, M., Kelkar, A., Kulkarni, M., De, A., Varaiya, A., 2003. An observational study to detect leptospirosis in Mumbai, India, 2000. Arch. Dis. Child. 88, 1070-1075.

Kleinbongard, P., Dejam, A., Lauer, T., Jax, T., Kerber, S., Gharini, P., Balzer, J., Zotz, R.B., Scharf, R.E., Willers, R., Schechter, A.N., Feelisch, M., Kelm, M., 2006. Plasma nitrite concentrations reflect the degree of endothelial dysfunction in humans. Free Radic. Biol. Med. 40, 295-302.

Ko, A.I., Reis, M.G., Ribeiro Dourado, C.M., Johnson Jr., W.D., Riley, L.W., 1999. Urban epidemic of severe leptospirosis in Brazil. Lancet 354, 820-825.

LaRocque, R.C., Breiman, R.F., Ari, M.D., Morey, R.E., Janan, F.A., Hayes, J.M., Hossain, M.A., Brooks, W.A., Levett, P.N., 2005. Leptospirosis during dengue outbreak, Bangladesh. Emerg. Infect. Dis. 11, 766-769.

Lin, C.L., Wu, M.S., Yang, C.W., Huang, C.C., 1999. Leptospirosis associated with hypokalaemia and thick ascending limb dysfunction. Nephrol. Dial. Transplant. 14, 193-195.

McBride, A.J., Athanazio, D.A., Reis, M.G., Ko, A.I., 2005. Leptospirosis. Curr. Opin. Infect. Dis. 18, 376-386.

Mitaka, C., Hirata, Y., Yokoyama, K., Wakimoto, H., Hirokawa, M., Nosaka, T., Imai, T., 2003. Relationships of circulating nitrite/nitrate levels to severity and multiple organ dysfunction syndrome in systemic inflammatory response syndrome. Shock 19, 305-309.

Nicodemo, A.C., Duarte, M.I., Alves, V.A., Takakura, C.F., Santos, R.T., Nicodemo, E.L., 1997. Lung lesions in human leptospirosis: microscopic, immunohistochemical, and ultrastructural features related to thrombocytopenia. Am. J. Trop. Med. Hyg. 56, 181-187.

Panaphut, T., Domrongkitchaiporn, S., Thinkamrop, B., 2002. Prognostic factors of death in leptospirosis: a prospective cohort study in Khon Kaen, Thailand. Int. J. Clin. Infect. Dis. 6, 52-59.

Rath, M., Krantz Jr., J.C., 1942. Nitrites VIII. Blood-nitrite content of man and other species. J. Pharmacol. Exp. Ther. 76, 27-32. 
Sarkar, U., Nascimento, S.F., Barbosa, R., Martins, R., Nuevo, H., Kalafanos, I., Grunstein, I., Flannery, B., Dias, J., Riley, L.W., Reis, M.G., Ko, A.I., 2002. Population-based case-control investigation of risk factors for leptospirosis during an urban epidemic. Am. J. Trop. Med. Hyg. 66, 605-610.

Siriwanij, T., Suttinont, C., Tantawichien, T., Chusil, S., Kanjanabuch, T., Sitprija, V., 2005. Haemodynamics in leptospirosis: effects of plasmapheresis and continuous venovenous haemofiltration. Nephrology (Carlton) 10, 1-6.

Tajiki, H., Salomao, R., 1996. Association of plasma levels of tumor necrosis factor alpha with severity of disease and mortality among patients with leptospirosis. Clin. Infect. Dis. 23, 1177-1178.

Tajiki, M.H., Nakama, A.S., Salomao, R., 1997. The ratio levels of IL10/TNF alpha and its relationship to disease severity and survival in patients with leptospirosis. Braz. J. Infect. Dis. 1, 138-141.

Tantitanawat, S., Tanjatham, S., 2003. Prognostic factors associated with severe leptospirosis. J. Med. Assoc. Thai. 86, 925-931.

Tavares-Murta, B.M., Zaparoli, M., Ferreira, R.B., Silva-Vergara, M.L., Oliveira, C.H., Murta, E.F., Ferreira, S.H., Cunha, F.Q., 2002. Failure of neutrophil chemotactic function in septic patients. Crit. Care Med. 30, 1056-1061.

Toprakci, M., Ozmen, D., Mutaf, I., Turgan, N., Parildar, Z., Habif, S., Guner, I., Bayindir, O., 2000. Age-associated changes in nitric oxide metabolites nitrite and nitrate. Int. J. Clin. Lab. Res. 30, 83-85.

Tsikas, D., 2006. Analysis of nitrite and nitrate in biological fluids by assays based on the Griess reaction: appraisal of the Griess reaction in the 1-arginine/nitric oxide area of research. J. Chromatogr. B, doi:10.1016/j.jchromb.2006.07.054.

Werts, C., Tapping, R.I., Mathison, J.C., Chuang, T.H., Kravchenko, V., Saint Girons, I., Haake, D.A., Godowski, P.J., Hayashi, F., Ozinsky, A., Underhill, D.M., Kirschning, C.J., Wagner, H., Aderem, A., Tobias, P.S., Ulevitch, R.J., 2001. Leptospiral lipopolysaccharide activates cells through a TLR2-dependent mechanism. Nat. Immunol. 2, 346-352.

Yang, G.G., Hsu, Y.H., 2005. Nitric oxide production and immunoglobulin deposition in leptospiral hemorrhagic respiratory failure. J. Formos. Med. Assoc. 104, 759-763.

Yang, C.W., Wu, M.S., Pan, M.J., Hsieh, W.J., Vandewalle, A., Huang, C.C., 2002. The Leptospira outer membrane protein LipL32 induces tubulointerstitial nephritis-mediated gene expression in mouse proximal tubule cells. J. Am. Soc. Nephrol. 13, 2037-2045.

Yang, C.W., Hung, C.C., Wu, M.S., Tian, Y.C., Chang, C.T., Pan, M.J., Vandewalle, A., 2006. Toll-like receptor 2 mediates early inflammation by leptospiral outer membrane proteins in proximal tubule cells. Kidney Int. 69, 815-822. 